\title{
A Torque Control Method of Reaction Wheel Driven by Coreless PMSM
}

\author{
Congrui QI, Zhiqiang WANG, Sen SU \\ School of Instrument Science and Opto-electronics Engineering, Beihang University, \\ Beijing 100191, China \\ Qicongrui0703@sina.com
}

\begin{abstract}
Modulation of a three phase inverter may generate serious torque ripples as a result of the small inductance of a coreless motor. In this paper, a control system with a LCL filter is first proposed to change the dynamic characteristics of the system and a torque control method of this specific system is proposed. First, the current command of four-leg system is alternating. Aiming at this issue, a robust tracking error cancellation controller which obtain high precision tracking and high dynamic performances is adopted. Second, the back EMF of motor contains harmonic component. Therefore, a new control method based on four-leg converter is proposed. This method can reduce power consumption of reaction wheel by controlling the zero sequence current interact with the harmonic of back EMF. Third, a new controller combining current feed forward and speed feedback is designed to improve the rapidity and accuracy of the torque. At last, simulation has been put into effect so as to prove the correctness and feasibility of this method.
\end{abstract}

Keywords: LCL filter, four-leg converter, robust, feed forward and feedback

\section{Introduction}

Reaction wheel is a key component of a satellite attitude control system. The wheel adjusts the attitude by means of the momentum exchange. So the precision of the output torque of the reaction wheel may affect the precision of satellite attitude directly [1-2]. In order to reduce power loss of the motor, most reaction wheels are driven by coreless motor. As a result, modulation of a three phase inverter may generate serious torque ripple. Besides, the torque command outputted by the attitude control computer is periodic and the reaction wheel operates alternately in acceleration and deceleration. Thus the dynamic characteristics of reaction wheel are of great significance.

A control system combining Buck converter and three-phase inverter is used in [3]. The control method of this system is PAM. However, this method uses DC side current as the feedback and controls torque indirectly. The accuracy of output torque is not ideal. Especially in the energy consumption braking phase, due to the small inductance characteristics of the motor, the modulation of DC side will cause current fluctuations. A reaction wheel system driven by PMSM is used in [4-6]. With three phase current as feedback, it completely eliminates the commutation torque ripples caused by square-wave drive. However, a core stator is used, so it does not apply the requirements of modern aerospace.

To acknowledge the tracking control of high-precision reaction wheels, a control system with a LCL filter and PMSM is proposed. Due to the introduction of the filter, a controllable rectification control system is proposed where three-phase current is feedback and torque control method is used. In addition, because of the zero-sequence current and zero-sequence counter electromotive force, a driven system based on four-leg is applied. It improves the use

Project Supported by National Natural Science Foundation of China (51107002) 
ratio of the current by engendering effective torque through the impact of zero-sequence current and zero-sequence counter electromotive force.

Fault-tolerant application is studied in [7]. Besides, four-leg converter has the ability to control zero-sequence current. Thus a control scheme composed of four-leg and LCL filter is proposed and the zero-sequence will generate positive torque together with harmonic back EMF. The LCL filter is used to eliminate the torque ripples. In the control system, the current references are alternating, so PID controller can't eliminate the steady-state error of current. Repetitive current control is used to reduce torque-ripple in PMSM but the algorithm is complex. Therefore, a robust tracking error cancellation controller is used in this paper. At last, a new controller combining current feed forward and speed feedback is designed to improve the rapidity and accuracy of the torque.

\section{Mathematical Model}

The three-phase inverter is widely used in ac drive and reactive power compensation. It adopts the structure of three bridge arms, which can generally give power supply to motors with three-phase balanced load. But for a specific application field, the threephase loads are changeable, which requires that the output is connected to the ground. So a control system with a LCL filter driven by four-leg converter is adopted. Then a bridge arm can be added to form the midpoint to acknowledge that. It has high straight utilization rate of current and its dc input capacitance is small. 1 .

The control system with a LCL filter driven by four-leg converter is shown in Figure

In order to calculate conveniently, the math model of four-leg converter will contain the inductor L and capacitor $\mathrm{C}$ of the filter. The model of PMSM will contain the equivalent value of the filtering inductance $\mathrm{L} 1$.

\subsection{Model of Four-Leg Converter}

After a feed forward decoupling, the mathematical model of four-leg converter can be written as [1-3].

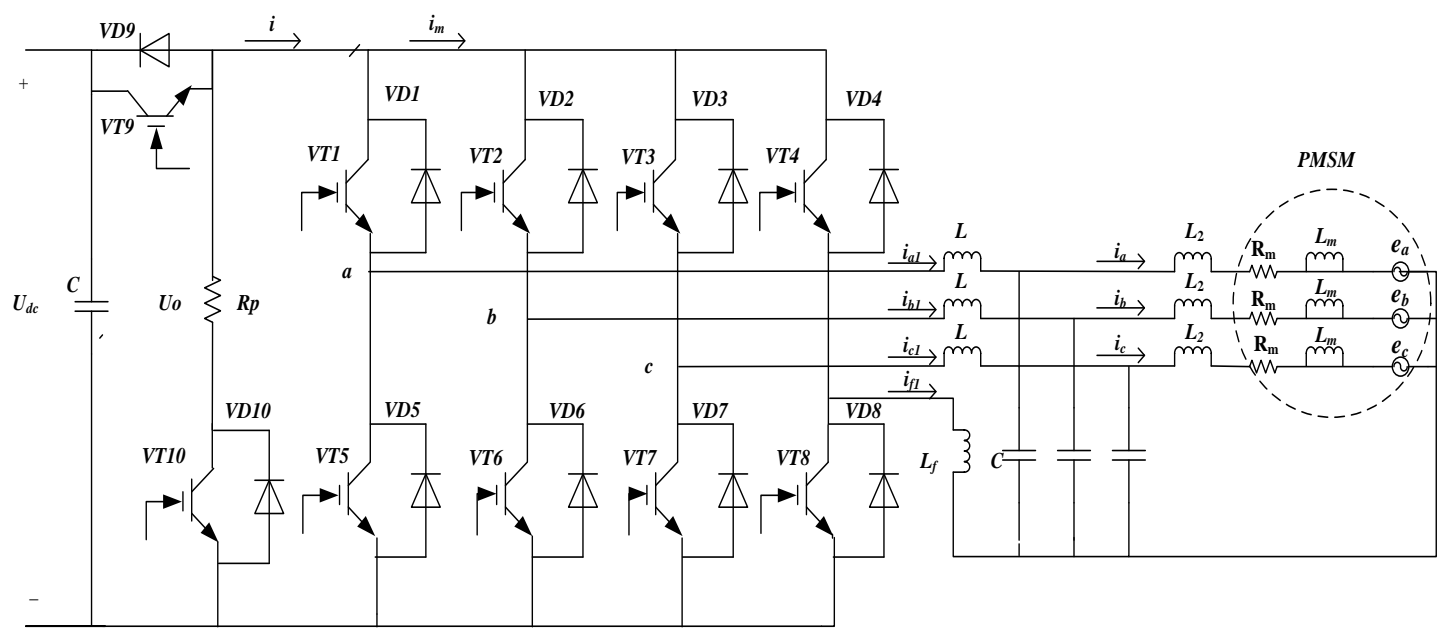

Figure 1. Control System with a LCL Filter Driven By Four-Leg Converter 


$$
\begin{gathered}
{\left[\begin{array}{c}
\cdot \dot{I}_{d} \\
\dot{I_{q}} \\
\dot{I_{o}}
\end{array}\right]=V_{g} G\left[\begin{array}{l}
d_{d} \\
d_{q} \\
d_{o}
\end{array}\right]-G\left[\begin{array}{c}
V_{d} \\
V_{q} \\
V_{o}
\end{array}\right]} \\
{\left[\begin{array}{c}
\dot{V_{d}} \\
\dot{V}_{q} \\
\dot{V}_{o}
\end{array}\right]=\frac{1}{C}\left\{\left[\begin{array}{c}
I_{d 1} \\
I_{q 1} \\
I_{o 1}
\end{array}\right]-G\left[\begin{array}{c}
I_{d} \\
I_{q} \\
I_{o}
\end{array}\right]\right\}} \\
G=\left[\begin{array}{ccc}
\frac{1}{L} & 0 & 0 \\
0 & \frac{1}{L} & 0 \\
0 & 0 & \frac{1}{L+3 L_{f}}
\end{array}\right]
\end{gathered}
$$

Where $\left[\begin{array}{lll}I_{d 1} & I_{q 1} & I_{o 1}\end{array}\right]^{T}$ and $\left[\begin{array}{lll}d_{d} & d_{q} & d_{o}\end{array}\right]^{T}$ are the values in d-q-o coordinate frame of $\left[\begin{array}{lll}I_{a 1} & I_{b 1}\end{array}\right.$ $\left.I_{c 1}\right]^{T}$ and the duty cycle of PWM $\left[\begin{array}{lll}d_{a f} & d_{b f} & d_{c f}\end{array}\right]^{T}$.

After decoupling, the four-leg converter is as effective as three Buck DC-DC converters. Thus the controller of $\mathrm{d}$-axis, $\mathrm{q}$-axis and o-axis can be design independently.

\subsection{Model of Reaction Wheel Driven by PMSM}

Assuming that the back EMF of the reaction wheel contains third harmonic, then the mathematical model of reaction wheel driven by PMSM in d-q-o coordinate frame can be express as (4) and (5),

$$
\begin{gathered}
{\left[\begin{array}{l}
V_{d} \\
V_{q} \\
V_{o}
\end{array}\right]=R\left[\begin{array}{l}
I_{d} \\
I_{q} \\
I_{o}
\end{array}\right]+\left[\begin{array}{ccc}
L_{d} & 0 & 0 \\
0 & L_{q} & 0 \\
0 & 0 & L_{o}
\end{array}\right] \frac{d}{d t}\left[\begin{array}{c}
I_{d} \\
I_{q} \\
I_{o}
\end{array}\right]+\left[\begin{array}{c}
e_{d} \\
e_{q} \\
e_{o}
\end{array}\right]} \\
{\left[\begin{array}{c}
e_{d} \\
e_{q} \\
e_{o}
\end{array}\right]=\omega_{e}\left[\begin{array}{c}
-L_{q} I_{q} \\
L_{d} I_{d}+\psi_{f} \\
\psi_{3} \sin \left(3 \theta_{e}\right)
\end{array}\right]}
\end{gathered}
$$

Where $\left[\begin{array}{llll}V_{d} & V_{q} & V_{o}\end{array}\right]^{T}$ and $\left[\begin{array}{lll}I_{d} & I_{q} & I_{o}\end{array}\right]^{\mathrm{T}}$ are the values of $\left[\begin{array}{lll}V_{a} & V_{b} & V_{c}\end{array}\right]^{T}$ and $\left[\begin{array}{llll}I_{a} & I_{b} & I_{c}\end{array}\right]^{T}$ in d-q-o coordinate frame, $\left[\begin{array}{lll}\mathrm{L}_{\mathrm{d}} & \mathrm{L}_{\mathrm{q}} & \mathrm{L}_{\mathrm{o}}\end{array}\right]^{\mathrm{T}}$ is the sum of the equivalent inductance of $\mathrm{L}_{2}$ and machine winding. $\theta_{\mathrm{e}}$ is the electrical position. $\Psi_{\mathrm{f}}$ and $\Psi_{3}$ are respectively the amplitude of first and third harmonics of flux linkages respectively.

Thus the electromagnetic torque of a surface-mounted PMSM is,

$$
T_{e}=\frac{3}{2} P\left(\psi_{f} I_{q}+\psi_{3} \sin \left(3 \theta_{e}\right) I_{o}\right)
$$


Where the first item and the second item are the electromagnetic torque generated by the current of q-axis and o-axis respectively.

\section{Control Method}

\subsection{Current Loop Design}

The current is minimized to generate same torque when the current is co-linear with the EMF. $I_{d}$ is kept to zero as it doesn't produce electromagnetic torque. Thus, the magnitude of current is,

$$
I=\sqrt{I_{q}^{2}+I_{o}^{2}}
$$

From (6), the torque is given by,

$$
T=k_{1} \sqrt{I_{s}^{2}-I_{o}^{2}}+k_{3}\left(\theta_{e}\right) I_{o}
$$

Where $k_{1}=\frac{3}{2} P \psi_{f}, k_{3}=\frac{3}{2} P \psi_{3} \sin \left(3 \theta_{e}\right)$

Then we can derive from (8) that if the current references are same with (9) under the torque reference $\mathrm{T}^{*}$, the magnitude of current will be minimum.

$$
\left\{\begin{array}{c}
I_{d}^{*}=0 \\
I_{q}^{*}=k\left(\theta_{e}\right) \psi_{f} T^{*} \\
I_{o}^{*}=k_{\left(\theta_{e}\right)} 2 \psi_{3}\left(3 \theta_{e}\right) T^{*}
\end{array}\right.
$$

$$
\text { Where } k_{\left(\theta_{e}\right)}=\frac{2}{3 P\left(\psi_{1}^{2}+\left(\sqrt{2} \psi_{3} \sin \left(3 \theta_{e}\right)\right)^{2}\right)}
$$

The current references Iq* and Io* are sine functions. Iq* is sixth harmonic and Io* is third harmonic. The traditional PID controller doesn't have the ability to track periodic signal with zero steady-state error and the algorithm of internal model control is complex although it is effective. Therefore, in order to improve the dynamic tracking feature of current loop, a robust tracking error cancellation controller shown in Figure 2 is proposed.

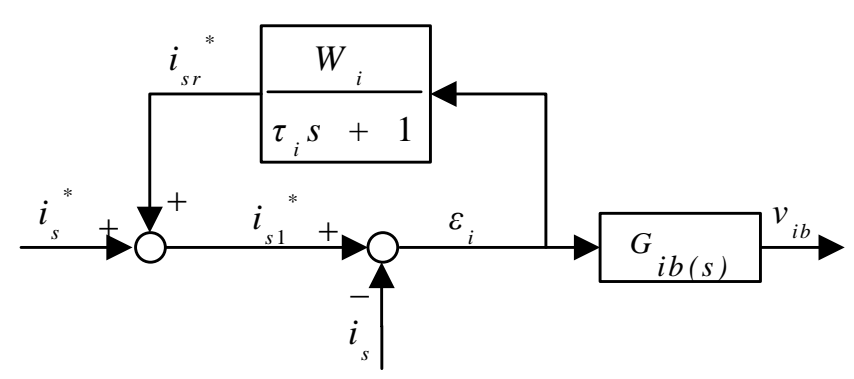

\section{Figure 2. Robust Tracking Error Cancellation Controller}

In Figure $2, \mathrm{G}_{\mathrm{ib}(\mathrm{s})}$ is a PI controller, ${ }_{i}{ }^{s}+1$ is a low-pass filter where $\mathrm{W}_{\mathrm{i}}$ is the feed-back factor. The controller will improve the tracking precision and speed of current loop using a positive feedback of current error $\varepsilon_{\mathrm{i}}$. Considering the speed of reaction wheel and frequency of PWM, the parameter of the controller is chosen as $\mathrm{W}_{\mathrm{i}}=0.5, \mathrm{r}_{\mathrm{i}}=0.0001$. 


\subsection{Feed Forward and Feedback Controller}

By using current feedback controller, the system can only realize electromagnetic torque emersion of torque command and doesn't have the ability to compensate disturbance. By using speed feedback controller, the accuracy of output torque will be improved. However, the delay of speed loop is very large as a result of large inertia of reaction wheel motor. Therefore, a control method combining current feed forward and speed feedback is proposed. The control scheme is shown in Figure 3.

It can be derive from (8) that,

$$
G_{T_{i}(s)}=\left[\begin{array}{c}
0 \\
k\left(\theta_{e}\right) \psi_{f} \\
k\left(\theta_{e}\right) 2 \psi_{3} \sin \left(3 \theta_{e}\right)
\end{array}\right]
$$

In order to make the proportion of $I_{d}$ the same as $I_{q}$ and make the current be co-linear with the EMF. The following function should be satisfied.

$$
G_{\omega_{i}(s)}=G_{T_{i}(s)}
$$

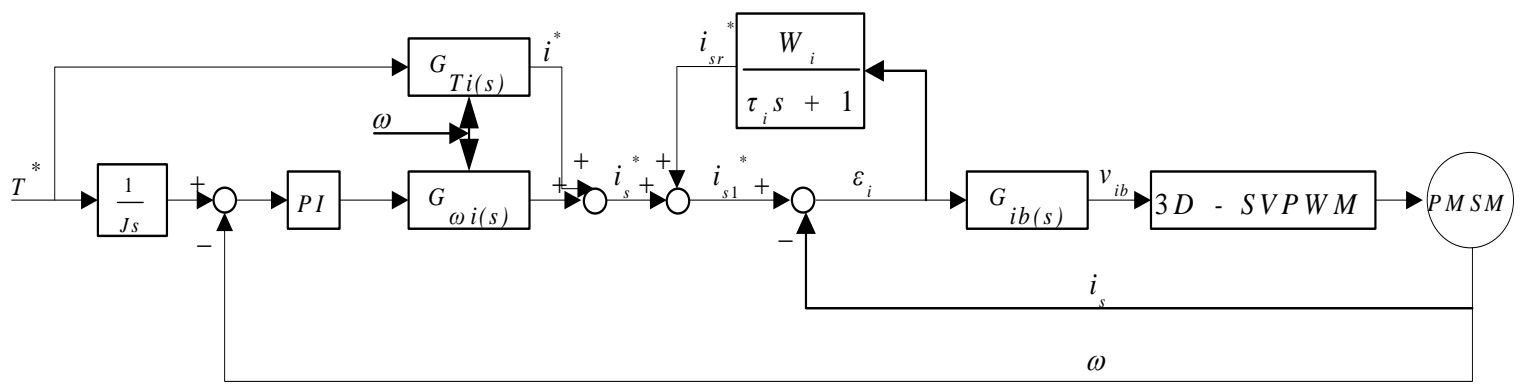

Figure 3. Control System

\section{Computer Simulation}

In order to verify the effectiveness of the proposed method, Matlab/Simulink simulation has been put into effect. Some major parameters are shown in Table 1.

Table 1. Major Parameters

\begin{tabular}{l|l}
\hline Specifications & Units \\
\hline Number of poles & 12 \\
\hline Moment of inertia, $J$ & $3.183 \times 10^{-6} \mathrm{~kg} \cdot \mathrm{m}^{2}$ \\
\hline Operated Speed & $6000 \mathrm{r} / \mathrm{min}$ \\
\hline Armature inductance, $L_{\mathrm{m}}$ & $5 \mu \mathrm{H}$ \\
\hline Phase resistance, $R_{\mathrm{m}}$ & $0.2 \Omega$ \\
\hline Inductance of the filter & $\mathrm{L}=1 \mathrm{mH}, \mathrm{L}_{2}=0.2 \mathrm{mH}$ \\
\hline Capacitor of the filter, C & $4.7 \mu \mathrm{F}$ \\
\hline Third harmonic of EMF & $20 \%$ \\
\hline
\end{tabular}

As is shown in Figure 4 to Figure 7, response curve of the reaction wheel when the torque 
command $\mathrm{T}=0.02 \mathrm{Nm}$ is given at $\mathrm{t}=1 \mathrm{~s}$. Figure 4 is the comparison of the $\mathrm{q}$-axis current response for PID controller and robust tracking error cancellation. The result shows that PID controller leads to lower dynamic characteristics and steady-state error goes larger with the increase of rotational speed. By using a robust tracking error cancellation controller, the current loop has higher dynamic response and the tracking error keeps little. This is because PID control method doesn't have the ability to track an alternating command without steadystate error, while the robust tracking error cancellation controller may improve the dynamic characteristic by applying a positive feedback of current error.

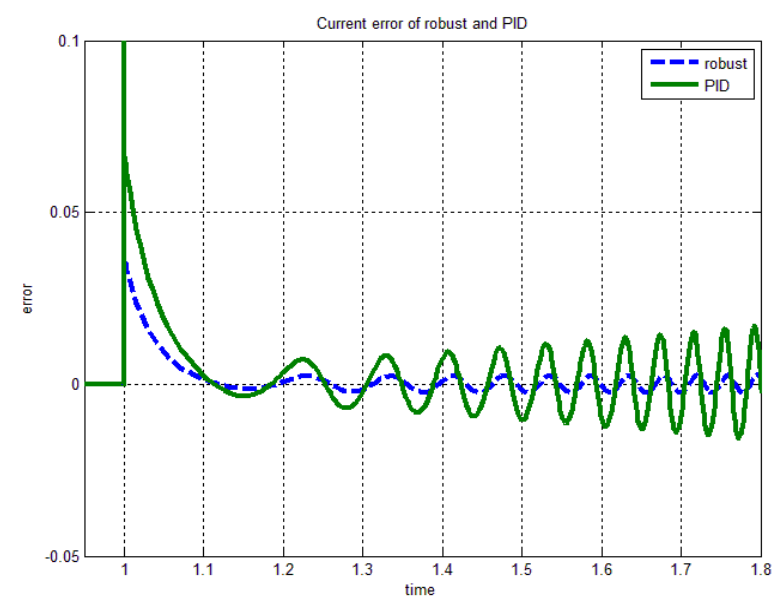

Figure 4. Comparison of Current Error for Tow Controllers: PID and Robust Tracking Error Cancellation.

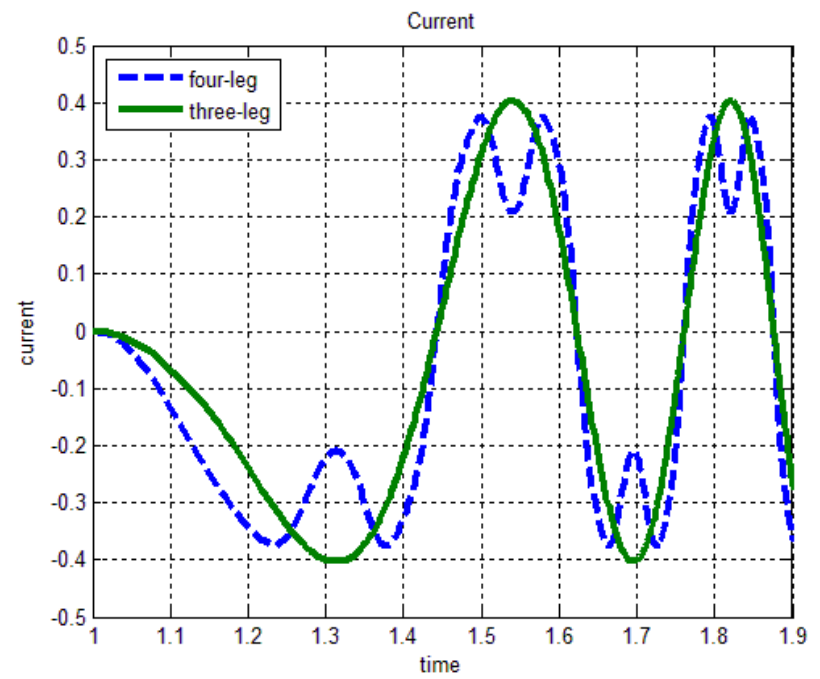

Figure 5. Current of the Reaction Wheel Driven By Four-Leg and Three-Leg Converter

What are shown in Figure 5 and Figure 6 are respectively winding current and power consumption of the reaction wheel driven by four-leg and three-leg converter. Using the method in this paper, the peak current and average current are lower. Thus the system driven by four-leg has greater efficiency. This is because the zero-sequence current is controllable in the four-leg system and can generate positive torque. 


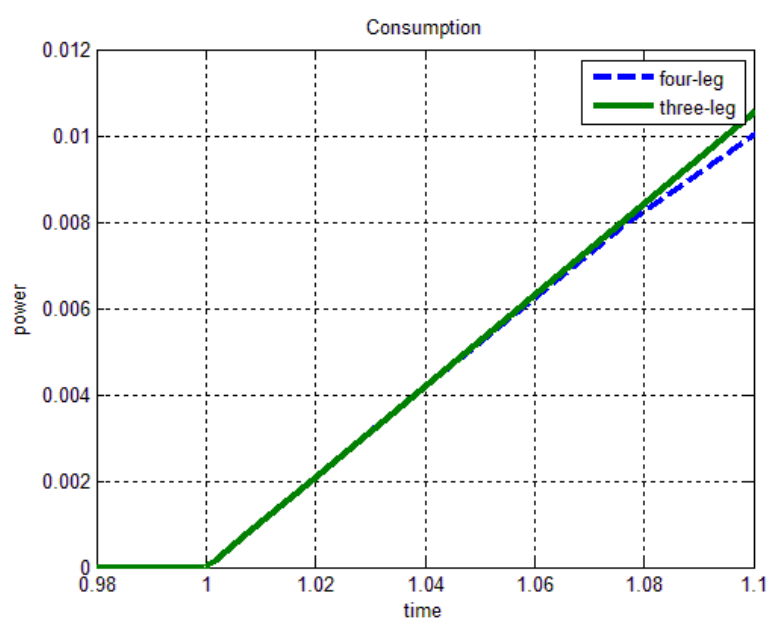

Figure 6. Power Consumption of the Reaction Wheel Driven By Four-Leg and Three-Leg Converter

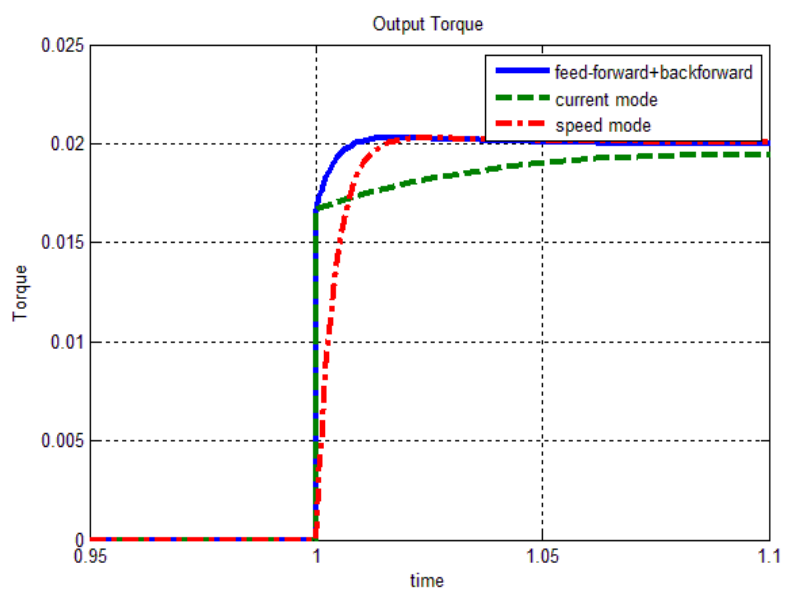

Figure 7. Torque Tracking Curves of the Systems Using the Control Method of Current Mode, Speed Mode and Feed Forward + Feedback

The torque tracking curves of the systems using the control method of current mode, speed mode and feed forward and feedback are shown in the Figure 7. The system using current mode has fast dynamic characteristics. But it does not eliminate the influence of disturbance torque. Speed mode can restrain the internal disturbance, but the dynamic characteristic of the system is poor because of the great rotary inertia of the motor and low sample rate of speed. Current feed forward and speed feedback controlling method can be used to balance the advantages of current mode and speed mode.

\section{Conclusion}

In this paper, a new control scheme is proposed aiming to realize high-precision torque control of the reaction wheel. A robust tracking error cancellation controller is adopted and a high precision tracking and high dynamic performances are obtained. By using a robust tracking error cancellation controller, fast current tracking performances without steady-state error are obtained. The consumption of reaction wheel is reduced thanks to the four-leg converter. At last, the control method combining current feed forward and speed feedback resolves the contradiction between quickness and accuracy of the reaction wheel torque. 


\section{References}

[1] J. Fang, X. Zhou and G. Liu, "Precise Accelerated Torque Control for Small Inductance Brushless DC Motor", IEEE Transactions on power Electronics, vol. 3, no. 28, (2013).

[2] J. Fang, X. Zhou and G. Liu, "Instantaneous Torque Control of Small Inductance Brushless DC Motor", IEEE Transactions on power Electronics, vol. 12, no. 27, (2012).

[3] T. Shi, Y. Guo, P. Song and C. Xia, "A New Approach of Minimizing Commutation Torque Ripple for Brushless DC Motor Based on DC-DC Converter”, IEEE Transactions on Industrial Electronics, vol. 10, no. 57, (2010).

[4] M. Chong and C. Liaw, "Development of Robust Current 2-DOF Controllers for a Permanent Magnet Synchronous M5tor Drive with Reaction Wheel Load", IEEE Transactions on power Electronics, vol. 5, no. 24, (2009).

[5] M.-C. Chong and C.-M. Liaw, "A Permanent-Magnet Synchronous Motor Drive for Reaction Wheel Application", XIX International Conference on Electrical Machines - ICEM, Rome, (2010).

[6] M. Chong and C. Liaw, "Dynamic Control and Diagnostic Friction Estimation for an SPMSMDriven Satellite Reaction Wheel”, IEEE Transactions on Industrial Electronics, vol. 10, no. 58, (2011).

[7] Khwan-on, S. De Lillo, L. Wheeler and P., "Fault tolerant four-leg matrix converter drive topologies for aerospace applications", Industrial Electronics (ISIE), (2010).

[8] P. Mattavelli, L. Tubiana and M. Zigliotto, "Torque-ripple reduction in PM synchronous motor drives using repetitive current control”, IEEE Trans. Power Electron, vol. 6, no. 20, (2005).

[9] I. Takahahsi and T. Noguchi, "A new quick-response and high-efficiency control of an induction motor", IEEE Trans.on IA, vol. 5, no. 22, (1986).

[10] T. Shi, L. Wei and X. Dan, "Sliding Mode Control of PMSM Based on Load Observer", 2010 International Conference on Electrical and Control Engineering, (2010).

\section{Authors}
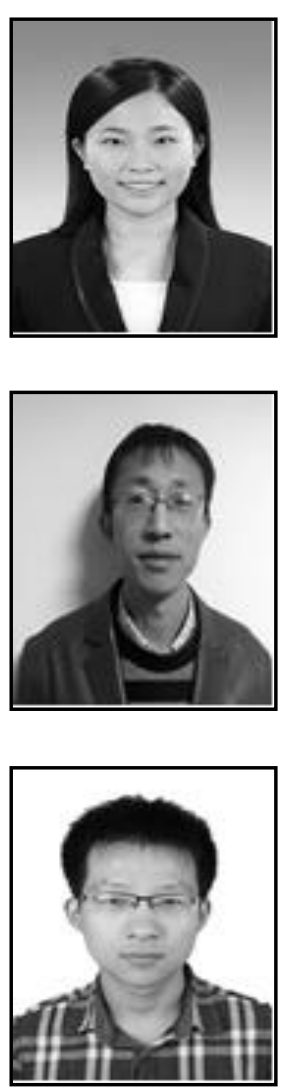

Congrui Qi, she is a Han nationality, native place: Beijing. Master graduate student, the main research direction is momentum wheel motor control technology. E-mail: Qicongrui0703@ sina.com
Zhiqiang Wang, he is a Han nationality, native place: Beijing. Ph.D. and lecturer, the main research directions are the motor servo control technology, momentum wheel motor control technology and so on. Email: wangzhiqiang@buaa.edu.cn

Sen Su, he is a Han nationality, native place: Beijing. Ph.D. and lecturer, the main research directions are the motor servo control technology, momentum wheel motor control technology and so on. Email: 460693476@qq.com 